\title{
CONGESTION CONTROL PADA JARINGAN KOMPUTER BERBASIS MULTI PROTOCOL LABEL SWITCHING (MPLS)
}

\author{
Ida Nurhaida \\ Fakultas Ilmu Komputer, Program Studi Teknik Informatika \\ Universitas Mercubuana \\ Email: ida.nurhaida@mercubuana.ac.id \\ Ichsan \\ Fakultas Ilmu Komputer, Program Studi Teknik Informatika \\ Universitas Mercubuana \\ Email: 41517110163@student.mercubuana.ac.id
}

\begin{abstract}
ABSTRAK
Pada saat jaringan MPLS mengalami kondisi network congestion di lintasannya, maka akan terjadi packet drop dan menyebabkan nilai $Q o S$ dari proses pengiriman data akan menurun. Penelitian ini dilakukan untuk menguji metode congestion control dengan penerapan QoS-Policies pada jaringan Multi Protocol Label Switching (MPLS). Parameter QoS (Quality of Services) yang diuji dalam penelitian ini berupa delay, troughput, jitter dan packet loss. Nilai-nilai yang didapatkan dari paramater tersebut kemudian dibandingkan dengan standar dari Telecommunications and Internet Protocol Harmonization Over Networks (TIPHON) dengan tujuan untuk mengetahui kualitas layanan pengiriman data pada jaringan MPLS ketika terjadi network congestion di lintasanya. Setelah melakukan proses perancangan, pengujian dan analisa, hasil yang didapat menunjukkan peningkatan nilainilai parameter $Q o S$. Nilai $Q o S$ untuk parameter delay mengalami penurunan sebesar 48.3\%, nilai troughput mengalami peningkatan sebesar $87.44 \%$, nilai jitter mengalami penurunan nilai sebesar $54.04 \%$ dan nilai packet loss mengalami penurunan sebesar $99.9 \%$.
\end{abstract}

Kata kunci: MPLS; congestion; $Q o S$.

\section{ABSTRACT}

When the MPLS network experiences network congestion on its path, packet drop will occur and the QoS value of the data transmission process will decrease. This research was conducted to test the congestion control method by implementing QoS-Policies on the Multi Protocol Label Switching (MPLS) network. QoS (Quality of Services) parameters tested in this study are delay, throughput, jitter and packet loss. The values obtained from these parameters are then compared with the standards of Telecommunications and Internet Protocol Harmonization Over Networks (TIPHON) with the aim of knowing the quality of data transmission services in MPLS networks when network congestion occurs in its location. After carrying out the design, testing and analysis process, the results obtained showed an increase in the values of the QoS parameters. The QoS value for the delay has decreased by 48.3\%, the throughput value has increased by $87.44 \%$, the jitter value has decreased by $54.04 \%$ and packet loss value has decreased by $99.9 \%$.

Keywords: MPLS; congestion; QoS.

\section{PENDAHULUAN}

Teknologi pengiriman paket data dalam jaringan komputer digunakan untuk kebutuhan yang semakin luas dan juga kompleks secara global. Tidak hanya mengirimkan paket data dari satu komputer ke komputer lainya, namun saat ini jaringan komputer dituntut untuk dapat melayani banyak host dalam satu waktu dengan jarak pengiriman yang semakin beragam.

MPLS (Multi Protocol Label Switching) merupakan jawaban dari kebutuhan teknologi pengiriman paket data saat ini, MPLS memiliki kemampuan membentuk tunnel atau virtual circuit yang melintasi network. Prinsip kerjanya menggabungkan beberapa keuntungan dari sistem komunikasi circuit-switched dan packet-switched. kemampuan inilah yang memberikan solusi arsitektur jaringan yang dapat digunakan secara massif dengan skala yang besar. MPLS merupakan teknologi terbaru yang digunakan oleh banyak provider untuk mengirim paket data pada jaringan backbone berkecepatan tinggi tanpa mengubah struktur jaringan yang telah ada sebelumnya. Sekarang ini banyak perusahaan yang jaringanya masih dilakukan secara manual mulai beralih memakai jaringan MPLS karena dianggap low cost dan high realibility(1). 
Ketika arsitektur MPLS dipakai secara massif dan berkepanjangan sebagai backbone untuk pengiriman data, tentu terdapat peningkatan arus trafik yang melewati jaringan MPLS tersebut. Pertumbuhan trafik yang tidak diimbangi dengan penambahan kapasitas skala jaringan MPLS akan mengakibatkan network congestion dibeberapa titik di sepanjang jaringan MPLS. Network congestion adalah kondisi dimana trafik yang lewat melebihi kapasitas dari jaringan tersedia, sebagai contoh terdapat aliran trafik sebesar 200Mbps sedangkan kapasitas jaringan yang dilewati hanya 100Mbps. Dengan kondisi tersebut maka akan terdapat packet drop yang menyebabkan packet loss. Ilustrasi kondisi network congestion ditunjukkan oleh gambar 1 dibawah.

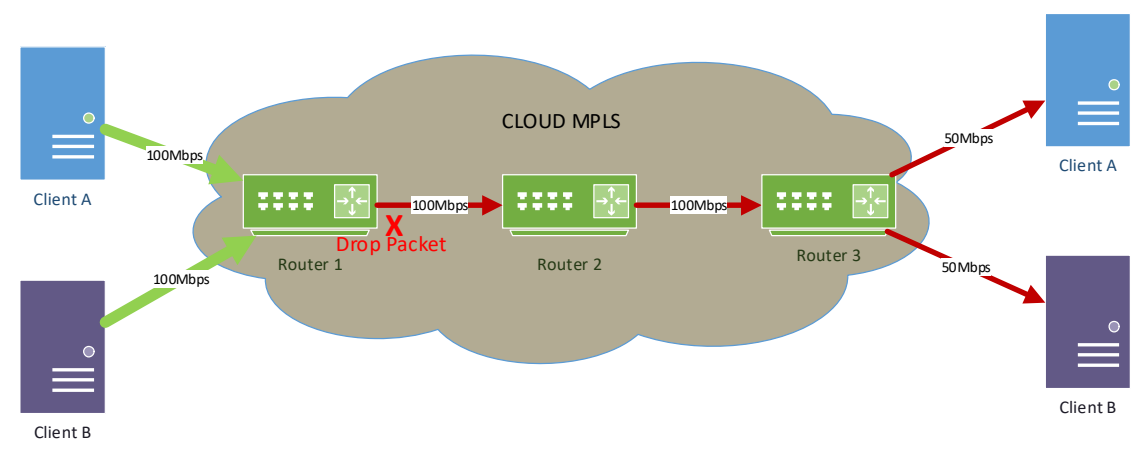

Gambar 1. Kondisi Network Congest

Congestion Control terdiri dari dua bidang yaitu TCP Congestion Control dan Active Queue Management. Keduanya mempunyai mekanisme berbeda. Active Queue Management adalah congestion control yang diterapkan dijaringan yaitu di router device(2). Pada penelitian ini digunakan congestion control Active Queue dengan memprioritaskan paket yang keluar dari router menggunakan forwarding class tertentu.

Kehandalan jaringan merupakan salah satu isu yang sering dibicarakan untuk jaringan best-effort (IP Based). Oleh karena itu teknologi Multi Protocol Label Switching (MPLS) digunakan untuk meningkatkan performansi jaringan. MPLS bekerja dengan cara menambahkan header/label pada paket sebagai identifikasi yang akan digunakan pada proses switching. Namun teknologi MPLS ini tetap tidak dapat memperhatikan kondisi jaringan. Sehingga apabila terjadi congest di jaringan tersebut maka tidak ada mekanisme tertentu untuk mengalihkan trafik ke jalur lain. Congestion tidak hanya terjadi pada jaringan MPLS saja. Semua teknologi pengiriman data mempunyai masalah yang sama. Seperti di bahas oleh Faishal H, Saputra dkk(3) melakukan survei mekanisme congestion control pada jaringan software defined network (SDN).

Semakin beragamnya layanan, mengakibatkan semakin banyak juga jenis paket yang akan dilewatkan di jaringan. MPLS mempunyai fitur QoS policies dapat menjadi solusi untuk menjaga $Q o S$ tiap layanan yang bekerja dengan cara mengelompokkan aliran trafik tertentu dalam sejumlah kelas-kelas trafik agar dapat memberikan perlakuan yang berbeda sesuai dengan standar kualitas setiap layanan. MPLS QoS policies merupakan metode congestion control yang dapat digunakan untuk membedakan perlakuan terhadap paket sesuai dengan jenis layanannnya dan dapat meminimalisir efek dari network congestion.

Dalam memitigasi network congestion terdapat beberapa metode yang umum dilakukan salah satunya adalah TCP congestion control mechanis. TCP merupakan protokol yang terdapat dalam OSI Layer di layer transport yang mendukung transfer mechanism data yang reliable, sehingga aliran data yang dibaca TCP receiver berurutan, utuh, tanpa duplisaki dan tidak rusak. Untuk menyediakan transfer data yang reliable, TCP menyediakan layanan flow control dan error checking. Ketika TCP sender mengirim data lebih cepat daripada yang bisa ditangani TCP receiver, maka akan terjadi congestion(4).

Namun ketika congestion terdapat di lintasan MPLS maka TCP congestion control mechanism tidak dapat digunakan karena TCP berada pada layer transport. Dalam lintasan MPLS sebuah packet hanya akan dibuka dan diperiksa sampai MPLS header yang letaknya diantara data link layer dan network layer pada setiap router dalam lintasan MPLS. Metode yang tepat untuk memitigasi congestion control pada jarigan MPLS dengan mengunakan Active Queue Management (AQM).

Active Queue Management (AQM) merupakan metode untuk mengatur congestion dan meningkatan $Q o S$. AQM mendukung jaringan MPLS dengan memanfaatkan mekanisme pengelompokkan DiffServ, memberikan tanda prioritas pada paket yang akan dikirimkan dalam jaringan. Sebelum paket dikirimkan melalui jaringan MPLS setiap paket akan diberi label DiffServ pada MPLS header. 


\subsection{MPLS (Multi Protocol Label Switching)}

MPLS adalah teknologi label-switching yang menggabungkan kemampuan rekayasa trafik ATM dengan fleksibilitas dan skalabilitas jaringan IP. MPLS memiliki kemampuan membentuk tunnel atau virtual circuit yang melintasi network. Prinsip kerjanya mengabungkan beberapa keuntungan dari sistem komunikasi circuit-switched dan packet-switched. MPLS memiliki arsitektur packet switching dan routing yang sangat baik dan dapat mengirimkan data dengan sangat cepat(5). Dalam jaringan MPLS juga mampu memisahkan setiap trafik customer yang berbeda walaupun menggunakan infrastuktur backbone secara bersamaan(6).

\subsection{Quality of Service (QoS)}

QoS adalah kemampuan untuk memberikan jaminan resources dan diferensasai layanan dalam jaringan(7). Prinsip kerjanya memberikan batasan-batasan tertentu dalam sebuah layanan dalam jaringan. Terdapat beberapa parameter untuk mengukur kualitas QoS diantaranya troughput, packet loss dan jitter. $Q o S$ saat ini menjadi parameter utama untuk mengukur kehandalan dari jaringan komputer, semakin tinggi nilai $Q o S$ yang didapat maka semakin handal jaringan komputer tersebut. Pada beberapa tahun sebelumnya teknologi pengiriman data ATM sangat banyak digunakan untuk mengirim data mendapat nilai $Q o S$ yang tinggi(8), namun terlalu rumit dan mahal untuk mengimplementasikan teknologi tersebut.

\subsubsection{Delay}

Delay adalah waktu yang dibutuhkan data untuk menempuh jarak dari asal ke tujuan (9). Tujuan pengukuran delay untuk mengetahui berapa lama waktu yang dibutuhkan untuk satu paket sampai dari sumber ke tujuan, pada penilitan ini delay yang di ukur merupakan one-way delay. Nilai delay yang ditampilkan dalam penilitan ini merupakan nilai rata-rata delay dari sepuluh kali percobaan di setiap skenario percobaan. Nilai delay yang sangat bagus menurut standar TIPHON adalah $<150 \mathrm{~ms}$. Tabel 1 menunjukkan nilai Delay menurut standar TIPHON:

Tabel 1. Nilai Delay Standar TIPHON(10)

\begin{tabular}{cc}
\hline Category & Delay \\
\hline Best & $<150 \mathrm{~ms}$ \\
Good & $150 \mathrm{~ms}-300 \mathrm{~ms}$ \\
Medium & $300 \mathrm{~ms}-450 \mathrm{~ms}$ \\
Poor & $>450 \mathrm{~ms}$ \\
\hline
\end{tabular}

\subsubsection{Troughput}

Throughput dapat diartikan sebagai jumlah data per satuan waktu yang dikirim di dalam sebuah jaringan, dari suatu titik jaringan ke titik jaringan yang lain(11). Tujuan pengukuran throughput adalah untuk mengetahui kehandalan jaringan dalam meneruskan paket yang datang hingga sampai di tujuan. Pengukuran dilakukan dengan melakukan pengiriman paket end to end melewati jaringan MPLS yang sudah terdapat network congestion, dengan menggunakan background trafik 10 Mbps, 50 Mbps dan 100 Mbps selama satu menit sebanyak 10 kali percobaan di setiap skenarionya. Nilai troughput yang ditampilkan pada hasil merupakan nilai rata-rata dari setiap percobaan. Tabel 2 menunjukkan nilai Troughput menurut standar TIPHON:

Tabel 2. Nilai Troughput Standar TIPHON(10)

\begin{tabular}{cc}
\hline Category & Troughput \\
\hline Best & $>2101 \mathrm{Kbps}$ \\
Better & $1201-2100 \mathrm{Kbps}$ \\
Good & $701-1200 \mathrm{Kbps}$ \\
Medium & $339-700 \mathrm{Kbps}$ \\
Poor & $0-338 \mathrm{Kbps}$ \\
\hline
\end{tabular}

\subsubsection{Jitter}

Jitter didefinisikan sebagai variasi delay yang diakibatkan oleh panjang antrean dalam suatu pengolahan data dan reassemble paket-paket data di akhir pengiriman akibat kegagalan sebelumnya(11). 
Jitter merupakan masalah yang khas pada connectionless atau packet switch network. Tujuan pengukuran jitter adalah untuk mengetahui kestabilan forwarding data dalam suatu jaringan. Kestabilan bisa dilihat dari banyaknya variasi delay yang terjadi selama waktu komunikasi di jaringan. Berdasarkan standar TIPHON nilai jitter yang sangat bagus adalah $0 \mathrm{~s} / \mathrm{d} 75 \mathrm{~ms}$. Tabel 3 menunjukkan nilai Jitter menurut standar TIPHON:

Tabel 3. Nilai Jitter Standar TIPHON (12)

\begin{tabular}{cc}
\hline Category & Jitter \\
\hline Perfect & $0 \mathrm{~ms}$ \\
Good & $75 \mathrm{~ms}$ \\
Medium & $125 \mathrm{~ms}$ \\
Poor & $225 \mathrm{~ms}$ \\
\hline
\end{tabular}

\subsubsection{Packet Loss}

Packet Loss adalah parameter yang menggambarkan suatu kondisi yang menunjukkan jumlah paket data yang hilang karena collusion atau congest didalam jaringan(13). Satuan yang dipakai adalah persen (\%). Tujuan pengukuran packet loss dilakukan untuk melihat kehandalan metode yang digunakan dalam mengiriman paket pada saat terjadi network-congestion. Berdasarkan standar TIPHON nilai packet loss yang sangat bagus adalah $0 \%$. Tabel 4 menunjukkan nilai Packet Loss menurut standar TIPHON:

Tabel 4. Nilai Packet Loss Standar TIPHON (12)

\begin{tabular}{cc}
\hline Category & Packet Loss \\
\hline Perfect & $0 \%$ \\
Good & $3 \%$ \\
Medium & $15 \%$ \\
Poor & $25 \%$ \\
\hline
\end{tabular}

\subsection{Forwarding-Class (FC)}

Router memiliki kemampuan membagi beberapa forwarding-class, cara kerjanya mengatur dan menangani bagaimana mekanisme paket di antrekan, antrean dibuat menurut prioritas masing-masing forwarding-class sebelum paket diteruskan ke dalam switch-fabric. Router memiliki delapan kelas forwading-class, seperti yang ditunjukkan pada tabel 5 dibawah:

Tabel 5. Tipe Forwarding Classses (14)

\begin{tabular}{cccc}
\hline FC-ID & FC Name & FC Designation & DiffServ Names \\
\hline 7 & Network Control & NC & NC2 \\
6 & High-1 & $\mathrm{H} 1$ & $\mathrm{NC} 1$ \\
5 & Expedited & $\mathrm{EF}$ & $\mathrm{EF}$ \\
4 & High- 2 & $\mathrm{H} 2$ & $\mathrm{AF} 4$ \\
3 & Low -1 & $\mathrm{~L} 1$ & $\mathrm{AF} 2$ \\
2 & Assured & $\mathrm{AF}$ & $\mathrm{AF} 1$ \\
1 & Low-2 & $\mathrm{L} 2$ & $\mathrm{CS} 1$ \\
0 & Best Effort & $\mathrm{BE}$ & $\mathrm{BE}$ \\
\hline
\end{tabular}

Secara umum forwarding-class terbagi menjadi tiga kategori utama yaitu, High-Priority, Assured dan Best-Effort. Dalam kategori high-priority terdapat empat kelas yaitu, network-controller (nc), expedited (ef), high 1 (h1), high 2 (h2). Kategori high-priority selalu menjadi prioritas teratas untuk dapat dilewatkan paket ketika terjadi network congestion. Pada kategori assured terdapat dua kelas yaitu, assured (af) dan low 1 (11). Kategori assured hanya menjamin paket sampai ketujuan jika bandwith dalam jaringan masih memungkinkan dan tidak terdapat kelas yang lebih tinggi di atasnya. Pada kategori besteffort terdapat dua kelas yaitu, low 2 (12) dan best-effort (be). Kelas best-effort tidak memiliki jaminan pengiriman, semua paket dalam kelas ini dikirim sesuai kemampuan bandwith. Kelas best-effort juga menjadi kelas default bagi pengiriman paket-paket MPLS. 


\subsection{Router}

Router bertugas meneruskan dan menentukan rute paket ke seluruh jaringan dari sumber ke tujuan akhirnya, proses tersebut dikenal dengan istilah routing(15). Proses routing terjadi pada lapisan 3 dari struktur $O S I$ dengan cara melihat alamat network dari setiap paket yang diproses, apabila sebuah paket mempunyai tujuan ke alamat host network yang berbeda, maka paket akan diteruskan ke alamat network tersebut, dan jika sebuah paket mempunyai tujuan ke alamat network yang sama maka router akan menghalangi paket tersebut keluar. Router menggunakan IP address tujuan untuk mengirimkan paket, dan agar router mengetahui rute mana yang harus digunakan untuk meneruskan paket ke alamat tujuan, router harus belajar atau bertukar informasi sesama router yang saling terhubung untuk mengetahui jalur atau rute yang terbaik(16).

\section{METODE PENELITIAN}

Metode desain jaringan yang digunakan dalam penelitian ini adalah PPDIOO (Prepare, Plan, Design, Implement, Operate and Optimize) yang juga dikenal dengan network lifecycle merupakan sebuah metode penelitian yang dikembangkan oleh Cisco System.Inc (17).

\subsection{Prepare}

Prepare merupakan tahapan awal proses penelitian untuk menyusun rencana kerja agar penelitian dapat berjalan dengan baik. Pada tahapan ini rencana terkait hal-hal yang berhubungan dengan analisa pokok pembahasan seperti permasalahan yang muncul, analisa kebutuhan penelitian dalam MPLS dan congestion control, baik itu dari segi hardware ataupun software dan analisa topologi jaringan yang akan dibangun.

\subsubsection{Perangkat Keras}

Dalam penelitan ini perangakat keras yang digunakan adalah sebagai berikut:

a. Router: Router berfungsi sebagai pengatur lalu lintas jaringan komputer, pada penelitian ini digunakan empat unit router merk NOKIA tipe 7210 SAS-M yang dapat mengaplikasikan konfigurasi jaringan $M P L S$ sesuai dengan standar $R F C-3031$

b. SFP (small form-factor pluggable): SFP berfungsi sebagai media interface di router untuk digunakan sebagai interface ke arah akses maupun ke arah network. Pada penelitian ini digunakan total dua belas unit $S F P$ dengan pembagian empat unit $S F P$ tipe $T X$ dan delapan unit $S F P$ tipe $L X$ dengan konektor tipe $L C$.

c. $P C$ Laptop: Laptop pada penelitian ini digunakan sebagai node client dalam jaringan $M P L S$, laptop juga berfungsi untuk menjalankan software untuk menguji kualitas layanan. Laptop yang digunakan dalam penelitian ini berjumlah 2 unit.

d. Kabel Patchcord: Patchcord pada penelitian ini digunakan sebagai media penghubung interface network antar router, dibutuhkan sebanyak empat unit patchcord single-mode dengan tipe konektor LC-LC.

e. Kabel UTP (Unshielded twisted-pair): Pada penelitian ini kabel UTP digunakan sebaga media penghubung interface akses dari router menuju laptop. Dibutuhkan empat unit kabel UTP dengan tipe $C A T-6$.

\subsubsection{Perangkat Lunak}

Dalam penelitian ini perangkat lunak yang digunakan adalah sebagai berikut:

a. Sistem Operasi Router: Router nokia memakai sistem operasi Timetra Operating-System (TiMOS), pada penelitian ini digunakan versi TiMOS-B-7.0.R5.

b. Sistem operasi $P C$ Laptop: Laptop yang digunakan dalam penelitian ini menggunakan sistem operasi windows 8 .

c. iperf V2: Berfungsi untuk melakukan inject trafik end to end antar laptop pada jaringan MPLS dengan skema background trafik $10 \mathrm{Mbps}, 50 \mathrm{Mbps}$ dan $100 \mathrm{Mbps}$. Iperf juga berfungsi untuk mengambil nilai troughput, jitter dan packet loss dalam setiap skenario pengujian.

d. Wireshark V3.0.0: Berfungsi melakukan pengamatan pengukuran nilai delay. 


\subsection{Plan}

Tahapan plan merupakan perencanaan jaringan yang dibuat baik segi software atau segi hardware yang dibutuhkan beserta rencana skenario pengujian yang dilakukan pada penelitian. Berikut flowchart diagram yang menjelaskan tahapan perancangan penelitian:

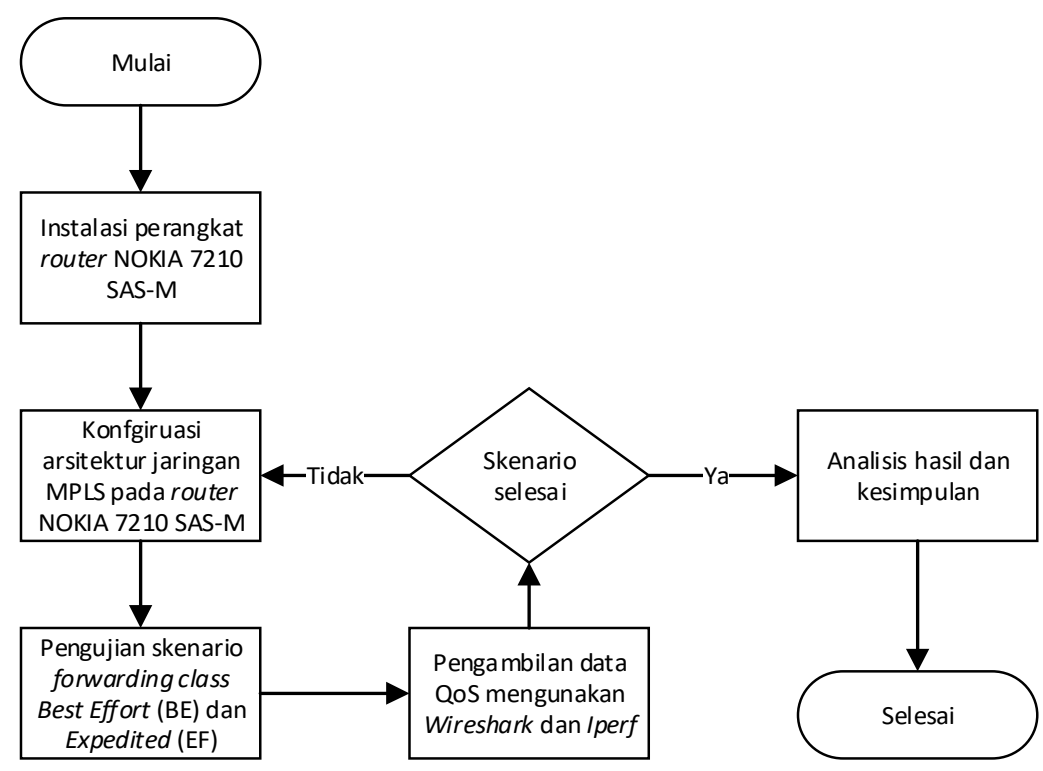

Gambar 2. Flowchart Perancangan Penelitian

Gambar 2 menunjukkan alur perancangan penelitian dimulai dengan instalasi perangkat router nokia, konfigurasi arsitektur MPLS sehingga semua router terhubung satu sama lain. Pengujian skenario congestion control mengunakan QoS policies best effort dan expedited, pengambilan data parameter QoS mengunakan Wireshark dan Iperf. Setelah data diambil maka proses selanjutnya menganalisa hasil dan menarik kesimpulan.

\subsection{Design}

Tahapan design merupakan tahapan membuat topologi jaringan yang akan diimplementasikan pada penelitian. Gambar 3 menunjukkan topologi yang dibangun pada penelitian ini :

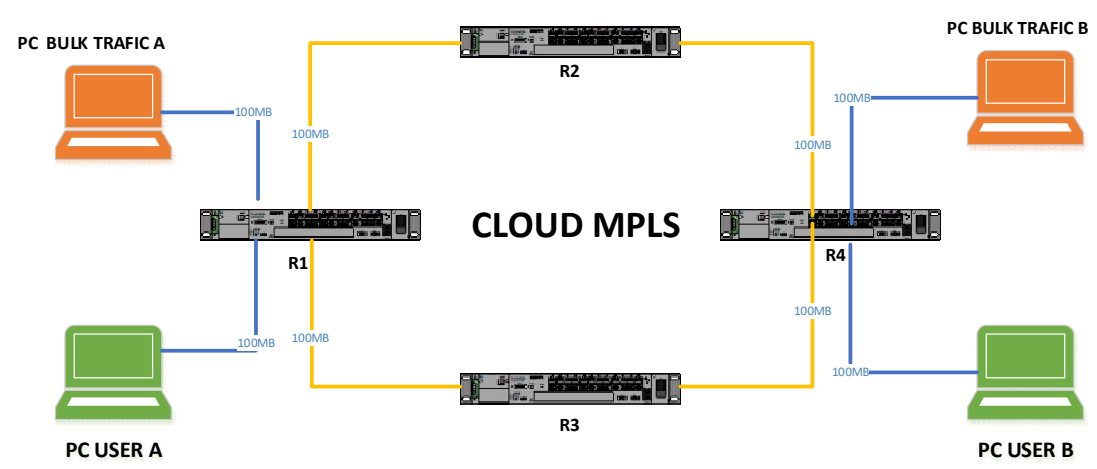

Gambar 3. Topologi Jaringan

Topologi jaringan MPLS yang dibangun menggunakan empat unit router nokia 7210 SAS-M dengan sistem operasi TiMOS versi TiMOS-B-9.0.R9, tabel 6 menunjukkan pengalamatan perangkat backbone $M P L S$. 
Tabel 6. Tabel pengalamatan device backbone MPLS

\begin{tabular}{cc}
\hline Perangkat & IP Address \\
\hline R1 & $10.10 .10 .1 / 32$ \\
R2 & $10.10 .10 .2 / 32$ \\
R3 & $10.10 .10 .3 / 32$ \\
R4 & $10.10 .10 .4 / 32$ \\
\hline
\end{tabular}

Router dibentuk dengan topologi ring dimana masing-masing router memiliki dua interface ke arah router lainya dengan kapasitas masing-masing interface sebesar 100 Mbps, tabel 7 menunjukkan pengalamatan interface.

Tabel 7. Tabel pengalamatan interface

\begin{tabular}{cccccc}
\hline Perangkat & Port & Tipe & IP Address & Nama Interface & Protokol \\
\hline $\mathrm{R} 1$ & $1 / 1 / 1$ & network & $192.168 .1 .1 / 30$ & to-r2 & OSPFv2, MPLS, RSVP, LDP \\
$\mathrm{R} 1$ & $1 / 1 / 2$ & network & $192.168 .1 .9 / 30$ & to-r4 & OSPFv2, MPLS, RSVP, LDP \\
$\mathrm{R} 2$ & $1 / 1 / 1$ & network & $192.168 .1 .2 / 30$ & to-r1 & OSPFv2, MPLS, RSVP, LDP \\
$\mathrm{R} 2$ & $1 / 1 / 3$ & network & $192.168 .1 .13 / 30$ & to-r3 & OSPFv2, MPLS, RSVP, LDP \\
$\mathrm{R} 3$ & $1 / 1 / 3$ & network & $192.168 .1 .14 / 30$ & to-r2 & OSPFv2, MPLS, RSVP, LDP \\
$\mathrm{R} 3$ & $1 / 1 / 1$ & network & $192.168 .1 .21 / 30$ & to-r4 & OSPFv2, MPLS, RSVP, LDP \\
$\mathrm{R} 4$ & $1 / 1 / 2$ & network & $192.168 .1 .10 / 30$ & to-r1 & OSPFv2, MPLS, RSVP, LDP \\
$\mathrm{R} 4$ & $1 / 1 / 1$ & network & $192.168 .1 .22 / 30$ & to-r3 & OSPFv2, MPLS, RSVP, LDP \\
\hline
\end{tabular}

Untuk melakukan inject trafik dan melakukan percobaan congestion control digunakan empat unit laptop $P C$ dengan sistem operasi Windows versi 8. Dua unit $P C$ mempunyai koneksi ke router R1 dan dua unit $P C$ mempunyai koneksi ke R4, koneksi antara $P C$ - router mengunakan kabel UTP tipe $C A T 6$.

\subsection{Implement}

Implement adalah tahap yang dilakukan sesuai pada topologi tahapan design. Mulai dari mempersiapkan arsitektur jaringan, melakukan instalasi software pada komputer laptop dan konfigurasi empat unit router nokia sebagai backbone MPLS. Melakukan inject trafik mengunakan aplikasi iperf, menganalisa hasil mengunakan aplikasi wireshark dan melakukan konfigurasi QoS policies pada router.

\subsection{Operate}

Operate merupakan tahap melakukan percobaan skenario yang telah disiapkan. Percobaan yang dilakukan dengan mengalirkan traffic bulk dari source ke destination menggunakan software iperf sehingga membuat lintasan MPLS terdapat network congestion. Pada host laptop PC User A dan B melakukan capture wireshark untuk menguji $Q o S$ dari skenario yang sudah ditetapkan dan pemecahan masalah yang timbul selama proses pengambilan data.

Dalam menguji kehandalan jaringan MPLS ketika terjadi network congestion di beberapa titik di sepanjang lintasan, maka dalam pengambilan data ada empat parameter $Q o S$ yang umum dilakukan pengukuran yaitu delay, troughput, jitter dan packet loss(18).

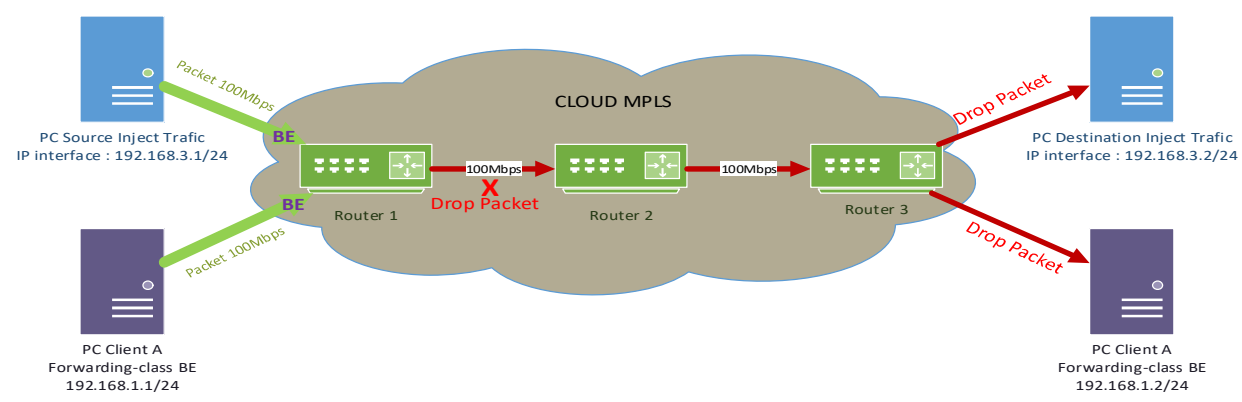

Gambar 4. Topologi Dengan Skenario Forwarding Class BE (Best-Effort) 
Pada dasarnya proses pengiriman dalam jaringan MPLS secara default menggunakan forwarding class best effort, seperti terlihat pada gambar 4, masing-masing $P C$ akan mengirimkan paket sebesar $100 \mathrm{Mbps}$, namum dengan kapasitas interface antar router yang hanya mampu melewati paket sebesar $100 \mathrm{Mbps}$ maka router akan melakukan drop paket dari kedua $P C$ dikarenakan forwarding class yang digunakan padat paket tersebut merupakan best effort class.

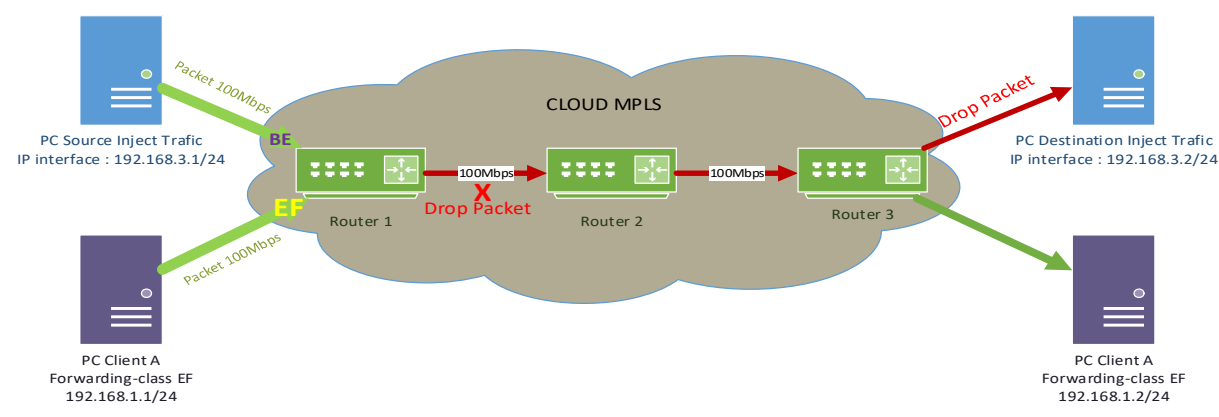

Gambar 5. Topologi Dengan Skenario Forwarding Class EF (Expedited)

Pada paket dengan forwarding class expedited (EF) yang ditunjukkan pada gambar 5, proses antrean paket selama proses pengiriman mendapatkan prioritas selama paket yang dikirim tidak melebihi dari kapasitas interface antar router dan paket-paket lainya memiliki forwarding class lebih rendah.

Poin utama yang diuji dalam penelitian ini yaitu menganalisa paket yang dilewati dalam jaringan MPLS yang telah terdapat network congestion di sepanjang lintasan menggunakan metode congestion control dengan forwading-class Best Effort (BE) dan QoS-Policies menggunakan forwarding-class Expedited (EF)

Setiap skenario pengujian pengiriman paket akan diberikan beban background trafik sebesar 10 Mbps, 50 Mbps dan 100 Mbps. Beban trafik yang digunakan mereplikasikan trafik full load, medium load dan low load trafik pada jaringan MPLS.

\subsection{Optimize}

Optimize merupakan tahapan optimalisasi setelah melakukan analisa pada tahapan operate, tahap ini dapat menyebabkan perlunya desain ulang jaringan apabila terlalu banyak masalah jaringan yang timbul atau kinerja tidak sesuai dengan yang diharapkan(19)

Setelah semua percobaan pada penelitian ini dilakukan dan didapatkan data percobaan, tahapan optimize tidak dilakukan dikarenakan tidak adanya masalah yang memerlukan desain ulang terhadap arsitektur jaringan $M P L S$ yang telah dirancang.

\section{HASIL DAN PEMBAHASAN}

Pada penelitian ini setelah melalui tahapan perancangan jaringan, konfigurasi jaringan MPLS, uji coba penerapan metode congestion control dengan menggunakan QoS Polices maka didapatkan nilai $Q o S$ dari masing-masing skenario pengujian, nilai $Q o S$ yang di uji pada penelitian ini berupa delay troughput, jitter dan packet loss.

\subsection{Delay}

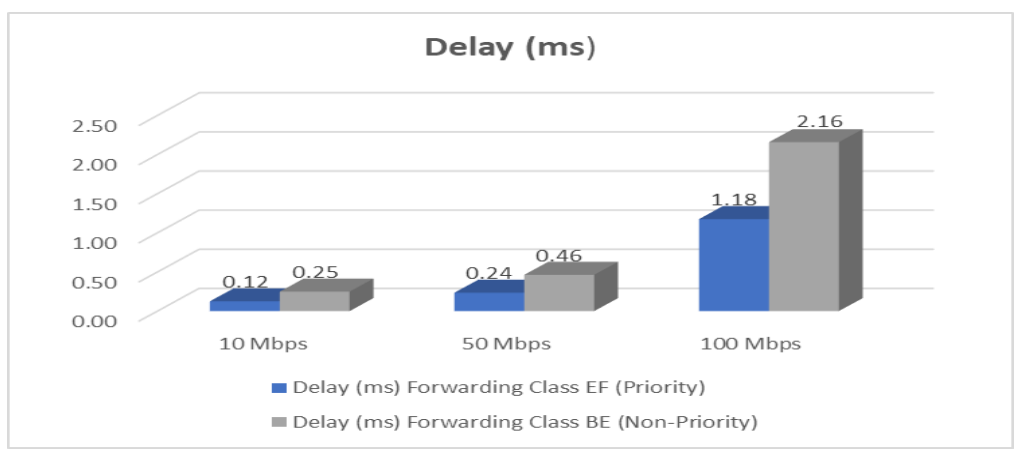

Gambar 6. Grafik Pengujian Delay 
Pada hasil pengujian delay menggunakan forwarding-class $\mathrm{EF}$ (priority) dan forwarding-class $\mathrm{BE}$ (non-priority) rata-rata dari sepuluh kali percobaan nilai delay dapat mencapai kategori best menurut standar TIPHON. Seperti yang ditunjukkan pada gambar 6 pengujian dengan background trafik $10 \mathrm{Mbps}$ parameter delay menunjukkan nilai $0.17 \mathrm{~ms}$ untuk forwarding-class EF dan $0.25 \mathrm{~ms}$ untuk forwardingclass BE, pada skenario pengujian dengan background trafik 50 Mbps delay yang dihasilkan $0.24 \mathrm{~ms}$ untuk forwarding-clas EF dan 0.46 ms untuk forwarding-class BE, pada pengujian dengan background trafik 100 Mbps delay menunjukkan nilai $1.18 \mathrm{~ms}$ untuk forwarding-class EF dan $2.16 \mathrm{~ms}$ untuk forwarding-class BE.

Dari hasil pengujian ini menunjukkan bahwa paket-paket yang diberikan label forwarding class EF (priority) mengalami peningkatan serta mendapatkan nilai delay yang lebih kecil dibandingkan dengan paket-paket dengan forwarding class BE (non-priority). Selain karena forwarding class yang diberikan pada paket $M P L S$, delay dapat dipengaruhi oleh jarak, media fisik, kondisi congest atau juga waktu proses yang lama. Titik-titik ini dapat berupa perangkat komputer, atau perangkat jaringan lainnya seperti router, modem dan sebagainya yang dilewati oleh paket(20).

\subsection{Troughput}

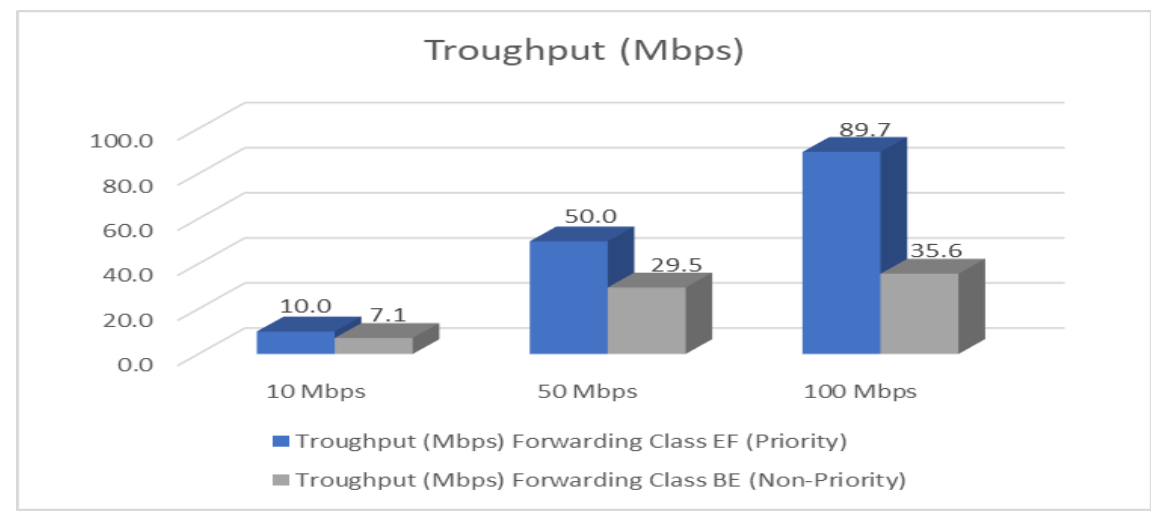

Gambar 7. Grafik Pengujian Troughput

Seperti yang ditunjukkan pada gambar 7 , hasil pengujian troughput dengan aliran trafik yang menggunakan forwarding-class EF (priority) rata-rata dapat mencapai nilai kategori best menurut standar TIPHON, pada background trafik 10 Mbps troughput mencapai nilai maksimal $10 \mathrm{Mbps}$, pada skenario pengujian 50 Mbps troughput yang dihasilkan mencapai nilai maksimal 50 Mbps sedangkan pada background trafik 100 Mbps troughput tidak mencapai angka maksimal $100 \mathrm{Mbps}$ hanya mencapai angka 89.7 Mbps, hal tersebut disebabkan karena keterbatasan resource dari kapasitas interface antar router sebesar 100 Mbps.

Pada hasil pengujian troughput menggunakan forwarding-class BE (non-priority) di background trafik $10 \mathrm{Mbps}$ troughput yang dihasilkan berada angka $7.1 \mathrm{Mbps}$, di background trafik 50 Mbps nilai troughput yang dihasilkan berada di angka $29.5 \mathrm{Mbps}$ dan di background trafik $100 \mathrm{Mbps}$ nilai troughput yang dihasilkan berada di angka $35.6 \mathrm{Mbps}$

Dari hasil pengujian ini menunjukkan bahwa paket-paket yang diberikan label forwarding class EF (priority) dapat melewati network congestion dan menjamin paket diterima dengan nilai troughput maksimal jika tidak terdapat keterbatasan resource pada jaringan. Sedangkan paket-paket yang diberikan label forwarding class BE (non-priority) jika melewati network congestion maka nilai troughput yang dihasilkan mengalami degradasi dan menjadi tidak maksimal.

Peningkatan sangat terlihat pada paket dengan forwarding-class EF (priority) dari ketiga skenario background trafik yang dilakukan pengujian, dua di antaranya dapat dicapai dengan hasil yang sangat baik, hal tersebut di sebabkan oleh proses queue yang diberikan oleh forwarding-class EF (priority) yang meberikan prioritas tinggi pada paket (21). 


\subsection{Jitter}

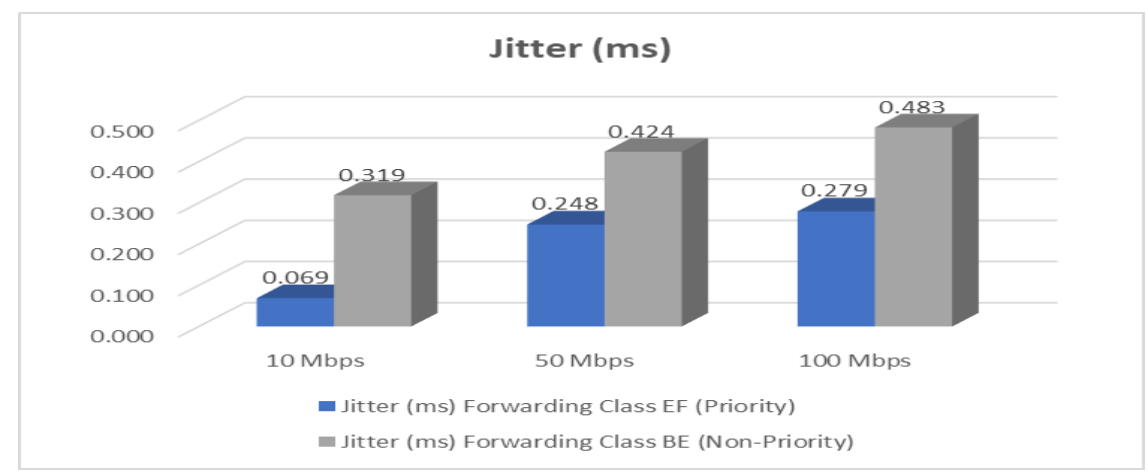

Gambar 8. Grafik Pengujian Jitter

Seperti yang ditunjukkan pada gambar 8 , hasil pengujian jitter yang didapatkan menunjukkan nilai $<$ $1 \mathrm{~ms}$ pada setiap skenario background trafik. Pada skenario pengujian dengan background trafik $10 \mathrm{Mbps}$ didapatkan angka $0.069 \mathrm{~ms}$ untuk forwarding-class EF (priority) dan $0.319 \mathrm{~ms}$ untuk forwarding-class $\mathrm{BE}$ (non-priority), pada skenario dengan background trafik 50 Mbps didapatkan angka $0.248 m s$ untuk forwarding-class EF (priority) dan $0.424 \mathrm{~ms}$ untuk forwarding-class BE (non-priority), pada skenario background trafik $100 \mathrm{Mbps}$ didapatkan angka $0.279 \mathrm{~ms}$ untuk forwarding-class EF (priority) dan 0.483 ms untuk forwarding-class BE (non-priority).

Dari hasil pengujian ini menunjukkan semua skenario pengujian masuk kategori sempurna menurut standar TIPHON untuk nilai jitter. Kondisi jitter dipengaruhi oleh berbagai macam aspek, salah satunya adalah jarak hop yang dilewati paket dari sumber ke tujuan, semakian banyak hop yang dilewati maka akan semakin besar variasi jitter yang dihasilkan(22). Pada pengujian ini semua skenario melewati tiga hop dari sumber hingga sampai ke tujuan hal tersebut yang menyebabkan hasil pengujian setiap skenario menunjukkan hasil sempurna.

\subsection{Packet Loss}

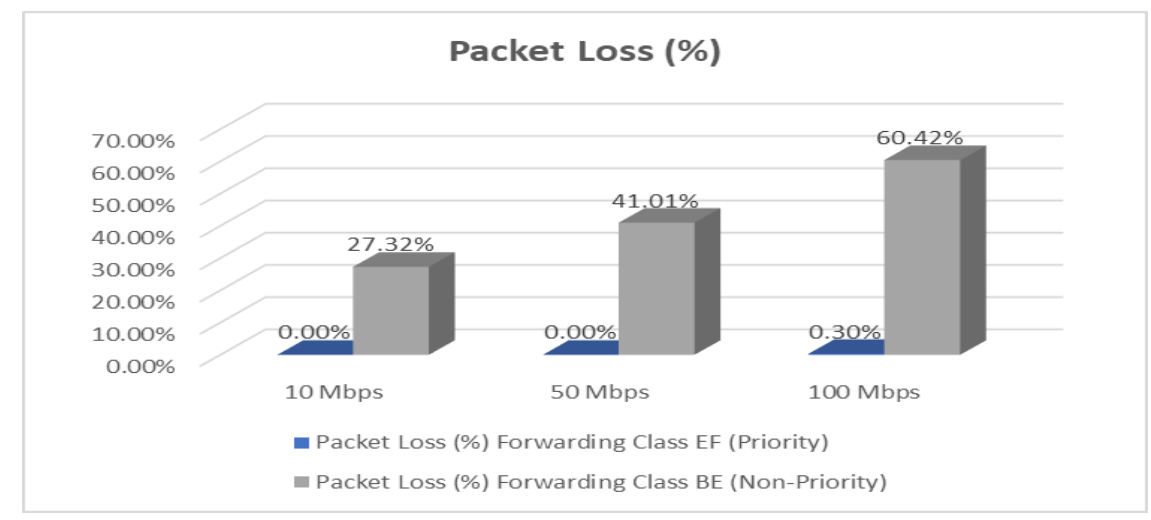

Gambar 9. Grafik Pengujian Packet Loss

Seperti yang ditunjukkan pada gambar 9, hasil pengujian packet loss yang menunjukkan nilai yang beragam pada setiap skenario background trafik. Pada skenario pengujian dengan background trafik $10 \mathrm{Mbps}$ didapatkan angka packet loss sebesar 0.00\% untuk forwarding-class EF (priority) dan $27.32 \%$ untuk forwarding-class BE (non-priority), pada skenario dengan background trafik 50 Mbps didapatkan angka $0.00 \%$ untuk forwarding-class EF (priority) dan $41.01 \%$ untuk forwarding-class BE (non-priority), pada skenario background trafik $100 \mathrm{Mbps}$ didapatkan angka $0.30 \%$ untuk forwarding-class EF (priority) dan $60.42 \%$ untuk forwarding-class BE (non-priority).

Dari hasil pengujian menunjukkan packet loss untuk forwarding-class EF (priority) telah memenuhi standar TIPHON, dimana semua hasil pengujian dengan tiga skenario background trafik mempunyai nilai kurang dari 3\% packet loss. Sedangkan untuk forwarding-class BE (non-priority) dimana semua hasil pengujian dengan tiga skenario background trafik rata-rata nilai packet loss yang dihasilkan sebesar $42.92 \%$ yang artinya sangat buruk menuruk standar TIPHON.

Packet loss bisa terjadi karena faktor bertambah banyaknya pengguna pada suatu jaringan yang saling tarik menarik bandwith(23). Dengan menggunakan QoS policies dapat ditentukan user atau host 
mana saja yang mendapatkan prioritas disaat terjadinya network congestion, sehingga dapat meminimalisir terjadinya packet loss.

\section{KESIMPULAN}

Berdasarkan hasil penelitian congestion control pada jaringan Multi Protocol Label Switching $(M P L S)$ selama proses perancangan infrastuktur, pengambilan data dan analisa hasil pada jaringan MPLS ketika terdapat congestion di sepanjang lintasanya. Maka dari penelitian ini dapat memberikan kesimpulan.

Pengambilan nilai-nilai parameter $Q o S$ dalam proses penelitian ini dibagi dalam tiga skenario background trafik yang mereplikasi kondisi high trafik dengan beban trafik 100 Mbps, medium trafik dengan beban 50 Mbps dan low trafik dengan beban 10 Mbps. Masing-masing skenario di uji dengan dua forwarding-class berbeda ketika terjadi network congestion. Forwarding class pertama menggunakan forwarding class BE (best-effort) yang kedua dilakukan optimalisasi menggunakan forwarding-class EF (expedited).

Setelah dilakukan optimalisasi dengan menggunakan forwarding-class EF, semua nilai paramater QoS yang di uji yaitu delay, troughput, jitter dan packet loss mengalami perubahan yang signifikan ketika paket MPLS melewati kondisi network congestion. Nilai $Q o S$ untuk parameter delay mengalami penurunan sebesar $48.3 \%$, nilai troughput mengalami peningkatan sebesar $87.44 \%$, nilai jitter mengalami penurunan nilai sebesar 54.04\% dan nilai packet loss mengalami penurunan sebesar 99.9\%.

Congestion control dengan menggunakan forwarding class Expedited (EF) merupakan hasil terbaik untuk mendapatkan nilai QoS yang optimal dan memenuhi standar TIPHON ketika terjadi network congestion di sepanjang lintasan MPLS.

Mekanisme antrean paket pengiriman pada forwarding class Expedited (EF) merupakan faktor yang paling mempengaruhi nilai-nilai parameter QoS ketika terjadi network congestion di sepanjang lintasan $M P L S$.

\section{DAFTAR PUSTAKA}

[1] Tjiptadi R. Sistem Jaringan Berbasis Vpn Dengan Metode Remote-Access. J Ilm Fifo. 2014; Vi(2):119-24

[2] Fajri M. Simulasi Antrian Paket Data Jaringan Dengan Mekanisme Drop Tail. J Ilm Fifo. 2016; Viii(2):151-60.

[3] Saputra Fh. Survei Mekanisme Congestion Kontrol Pada Transmission Control Protocol Di Software Defined Network. Juti J Ilm Teknol Inf. :1-9.

[4] Harfad At, Akbar Sr, Bhawiyuga A. Analisa Kinerja Algoritma Tcp Congestion Control Cubic , Reno, Vegas Dan Westwodd+. J Pengemb Teknol Dan Ilmu Komput. 2018;2(3):1099-108.

[5] Soewito B, Gunawan Fe, Afdhal S, Antonyova A. Analysis Of Quality Network Using Mpls And Non Mpls. 2017 Int Semin Intell Technol Its Appl Strength Link Between Univ Res Ind To Support Asean Energy Sect Isitia 2017 - Proceeding. 2017;2017-Janua:1-4.

[6] Hundley K. Alcatel-Lucent Scalable Ip Network Nrs1. Wiley Publishing, Inc.; 2009. 430-431 P.

[7] Othman Az, Rahman Ra, Md Zan Mm, Yusof Mi. The Effect Of Qos Implementation In Mpls Network. Ieee Symp Wirel Technol Appl Iswta. 2012;321-6.

[8] Han L, Wang J, Wang C. A Variable Forwarding Equivalence Class For Mpls Networks. 2009 Int Conf Multimed Inf Netw Secur. 2009;0-3.

[9] Sitohang S. Implementasi Jaringan Fiber To The Home ( Ftth ) Dengan Teknologi Gigabit Passive Optical Network ( Gpon ). J Simetris. 2018;9(2):879-88.

[10] Susandi H, Pinem M. Analisis Kualitas Layanan Data Pada Jaringan Telekomunikasi Berbasis Cdma Evdo Rev . A. Singuda Ensikom. 2014;6(2):93-8.

[11] Wedda App, Mayasari R, Elektro Ft, Telkom U, Play Lt. Implementasi Dan Analisis Soft Qos ( Diffserv ) Pada Jaringan Mpls - Te Untuk Layanan Triple Play Implementation And Analysis Of Soft Qos ( Diffserv ) On Mpls-Te. E-Proceeding Eng. 2015;2(2):2916-24.

[12] Tiphon. General Aspects Of Quality Of Service (Qos). Vol. 1. 1999.

[13] Nurhaida I, Ngadiyono. Quality Of Service For Traffic Monitoring System Based On Static Routing Using Eoip Tunnel Over Ipsec. Proc 2019 Asia Pacific Inf Technol Conf. 2019;(1):1-9.

[14] Alcatel-Lucent. Qos Policies. 2015.

[15] Hundley K. Alcatel-Lucent Scalable Ip Network Self-Study. Wiley Publishing, Inc.; 2009.

[16] Kusniyati H, Yusuf R, Wiraka Bc. Analisis Kinerja Routing Protokol Ripng Dengan Ospfv3 Pada Jaringan Ipv6 Tunneling. J Pengkaj Dan Penerapan Tek Inform. 2017;10(2):56-63.

[17] Wilkins. S. Cisco's Ppdioo Network Cycle. 2011.

[18] Wulandari R. Analisis Qos ( Quality Of Service ) Pada Jaringan Internet ( Studi Kasus : Upt Loka 
Uji Teknik Penambangan Jampang Kulon - Lipi ). J Tek Inform Dan Sist Inf. 2016;2:162-72.

[19] Dian L, Saputra D, Sulistyo W. Analisis Qos Differentiated Service Pada Jaringan Mpls. J Teknol Inf Dan Ilmu Komput. 2017;4(4):227-36.

[20] Naraswari N, Imansyah F, W Ftp. Analisis Uji Kuat Sinyal Terhadap Jarak Jangkau Maksimal Sistem Penerimaan Sinyal Internet Berbasis Edimax Hp-5101ack. J Fak Tek Univ Tanjungpura. 2017;

[21] Barry Ma, Tamgno Jk, Lishou C, Cissé Mb. Qos Impact On Multimedia Traffic Load ( Iptv , Roip , Voip ) In Best Effort Mode. Int Conf Adv Commun Technol. 2018;694-700.

[22] Kandar S, Bhunia, C T. A New Protocol For Minimizing Jitter For Guaranteed Qos In Network Multimedia Communication. 2010 Int Conf Adv Comput Eng. 2010;(1):15-8.

[23] Nasir J, Andrianto E. Implementasi Quality Of Service , Limit Bandwidth Dan Load Balancing Dengan Menggunakan Firmware Dd-Wrt Pada Router Buffalo Whr-Hp-G300n. J Simetris. 2018;9(1):403-12. 